\title{
Inbreeding and Mortality Risk in a Captive Population of Mhorr Gazelle (Nanger dama mhorr)
}

\author{
Ana Marquiza M. Quilicot and Roswitha Baumung
}

\author{
Division of Livestock Sciences, University of Natural Resources and Life Sciences \\ (BOKU) Vienna, Austria
}

\section{ABSTRACT}

This study aimed to evaluate the genetic variation and examine the association of inbreeding level on mortality risk (at days 7,30 and 180-weaning age) of Mhorr gazelle in captivity for the year 1969-2000 as recorded in the studbook record kept by Australasian Regional Association of Zoological Parks and Aquaria (ARAZPA). The effective number of founders, ancestors and founder genomes was found to be $3.42,3$, and 1.44 for the studied reference population. The reference population is composed of animals which are alive, with known parents and known sex. Animals that are less than 10 years old (based on birth dates up to 2008) with no remarks on its death are considered alive. The population may not have experienced a severe bottleneck, as the values on the effective number of founders and ancestors are almost equal. However, the effective number of founder genomes is low, which demonstrates gene loss due to genetic drift. The mean inbreeding coefficients of the individual, sire and dam were found to be 0.2971 $\pm 0.1043,0.2300 \pm 0.11410 .2339 \pm 0.1070$, respectively. The maximum inbreeding level of the population is 0.5247 (52.47\%). This means that parent-offspring or full-sib mating must have happened. The increase in inbreeding level of an individual was found to be significantly associated $(p<0.10)$ with an increase in mortality risk at day 180 or weaning age. Increasing inbreeding level of sires was found to be significantly associated with increasing risk in mortality at day 30, which indicates that inbred parents also can influence the survival of an offspring. Efficient breeding programs are as important for decreasing mortality in captive populations, as the provision of optimum zoo management practices.

Keywords: genetic diversity, genetic variation, inbreeding, captive population, Mhorr gazelle, mortality

\section{INTRODUCTION}

Controlled breeding of captive animal populations which are endangered or threatened has become an important approach to maintain genetic diversity and avoid inbreeding depression (Hedrick, 1994). However, population sizes in zoos are usually small, which may lead to reduction of genetic diversity and inbreeding. The reduction of genetic diversity increases extinction risk of a captive population. Inbreeding may result in inbreeding depression (Frankham et al., 2001), thus decreasing the performance of inbred individuals. 
Genetic variation can be evaluated by evaluating the probability of gene origin using the population's pedigree record. Probability of gene origin can be determined by calculating the founder equivalents (effective number of founders), effective number of ancestors, and founder genome equivalent (effective number of founder genes or genomes). These measures are commonly used in wild populations. Ancestors, especially those that were caught in the wild, are considered founders when the parents are unknown (Lacy, 1989). Effective number of founders or founder equivalent is the number of founders having equal genetic contribution and expected to produce the same genetic diversity of the population being studied. However, bottlenecks are not accounted for in this measure (Lacy, 1989; Boichard et al., 1997). When the effective number of founders equals the actual number of founders, genetic diversity is maintained and there is equal contribution among founders. However, in real situations, effective number of founders is usually smaller than the actual number of founders (Lacy, 1989; Boichard et al., 1997). The number of equally contributing ancestors to genetic diversity of a population refers to the effective number of ancestors. This measure takes into account the possible bottleneck(s) experienced by the population. In most situations the effective number of ancestors is smaller than the effective number of founders (Boichard et al., 1997). The effective number of founder genes or genomes is the number of equally contributing founders with no random loss of founder alleles in the offspring. It is expected to produce the same diversity as in the population under study. This measure estimates if the genes from the founders are still present in the population under study. The effective number of founder genes or genomes is usually smaller than the effective number of ancestors since this measure considers gene loss due to unequal founder contribution, bottlenecks and random genetic drift (Lacy, 1989; Boichard et al., 1997).

To investigate the level of inbreeding, inbreeding coefficient $(f)$ can be calculated. Inbreeding coefficient $(f)$ is defined as the probability that the two alleles in any homologous locus of an individual are identical by descent originating from a common ancestor of the parents at the same time indicating the relationship between the parents of the individual (Falconer and Mackay, 1996). Inbreeding may result in inbreeding depression, which is an important concern among endangered species. It affects fitness traits (Hedrick \& Kalinowski, 2000); however, due to differences in the genetic makeup of the animals and genotype-environment interaction, the degree to how the population will react is variable. On one hand, the increase in the frequency of homozygotes for deleterious alleles will result in elimination of these alleles; thus, the genetic load is purged. Hedrick (1994) mentioned that theoretically, purging will result in an increase in fitness when a population is randomly mating with a balance of mutation and selection.

This study focused on the captive population of Mhorr gazelle Nanger dama mhorr) which is a subspecies of Dama gazelle Nanger dama). These animals inhabit the Atlantic Sahara of Africa. The International Union for Conservation of Nature (IUCN) declared the Mhorr gazelle as critically endangered (Newby et al., 2008). This study aimed to (1) evaluate the genetic diversity and (2) examine the association of inbreeding level to mortality (at days 7,30 and 180-weaning age) of Mhorr gazelle population as recorded in the studbook for the year 1969-2000. 


\section{MATERIALS AND METHODS}

Data

The data from the studbook records of Mhorr gazelle in SPARKS (Single Population Analysis and Records Keeping System) format of the Australasian Regional Association of Zoological Parks and Aquaria (ARAZPA), which were last updated on March, 2002, was used for analysis in this study. The following information was used in the analysis: identity number of the individual, sire and dam; sex; birth date; death date or date indicating the last update of the individual in the studbook; parity number and location of birth (zoo). Table 1 shows the summary of the data and pedigree structure of Mhorr gazelle captive population.

Table 1. Summary of the data and pedigree structure of Mhorr gazelle.

\begin{tabular}{ll}
\hline & \multicolumn{1}{c}{ Mhorr gazelle } \\
\hline No. of animals in the pedigree & 315 \\
No. of living animals & $97(30.79 \%)$ \\
No. of males & $148(46.98 \%)$ \\
No. of females & $167(53.02 \%)$ \\
No. of sires with offspring & $36(11.42 \%)$ \\
No. of dams with offspring & $72(22.86 \%)$ \\
No. of parities & 308 \\
Parity number, mean \& range & $4.35(1-15, \mathrm{SD}=3.38)$ \\
Pedigree record period & $1969-2000(31 \mathrm{y})$ \\
No. of zoos with the species & 16 \\
\hline
\end{tabular}

\section{Data Management and Analysis}

The studbook record data was organized using Microsoft Excel and was analyzed using the PEDIG software package by Baumung et al. (2015) and SAS procedure GLIMMIX (v. 9.2 Statistical Analysis Systems Institute Inc., Cary, NC).

Measures of genetic diversity (founder equivalents or effective number of founders, effective number of ancestors, and founder genome equivalent or effective number of founder genes or genomes) and individual inbreeding coefficient were calculated using the GRain program (Baumung, et al., 2015).

With SAS procedure GLIMMIX (v. 9.2 Statistical Analysis Systems Institute Inc., Cary, NC), the general linear mixed model was used to evaluate the influence of inbreeding on day 7, day 30 and day 180 (weaning age). Survival to day 30 is included in the analysis to have additional mortality records. The individual, sire and dam inbreeding coefficients were included in analyses, together with sex, parity number and birth type as shown in the model below:

$$
u=u_{0}+\beta f+\beta_{f f} f_{s}+\beta_{f d} f_{d}+\beta_{\mathrm{Sex}} \mathrm{Sex}+\beta_{\text {Parityy }} \text { Parity } \#+\beta_{\text {BirthType }}
$$


Where $\mathrm{u}$ is the logit transformation of a measure of fitness such as mortality, $\mathrm{u}_{0}$ is the mean fitness of non-inbred animals, $\mathrm{f}$ is the total inbreeding coefficient of the individual/litter, $f_{s}$ is the total inbreeding coefficient of the sire, $f_{d}$ is the total inbreeding coefficient of the dam, Sex is the sex of the individual, Parity\# is the parity number (1-10), and $\beta_{\mathrm{f}}, \beta_{\mathrm{fs}}, \beta_{\mathrm{fd}}, \beta_{\mathrm{Sex}}$, and $\beta_{\text {Parity }}$ are the regression coefficients associated with $f, f_{s}, f_{d}$, Sex, and Parity\#, respectively.

Each individual was coded as either not surviving/mortality (0) or surviving (1) at day 7, day 30 or day 180 (weaning age). Excluded in the analyses are individuals with missing death dates and no update on information. Parity numbers beyond 10 were clustered to 10 . Data restrictions were made based on the species and the number of observations per zoo-year combination. Zoo-years with only one observation were excluded from the analyses for all survival traits.

The significance of the different inbreeding coefficients (at $p<0.10$ ) to survival was analyzed with SAS procedure GLIMMIX (v. 9.2 Statistical Analysis Systems Institute Inc., Cary, NC).

The mortality risk of an individual or litter at days 7, 30 and 180 (weaning age) at a certain level of inbreeding was calculated based on the formula below (Agresti, 2002):

$$
\hat{\boldsymbol{\pi}}(\boldsymbol{x})=\frac{\exp (\text { intercept }+ \text { parameter estimate } \boldsymbol{x})}{1+\exp (\text { intercept }+ \text { parameter estimate } \boldsymbol{x})}
$$

where $\hat{\boldsymbol{\pi}}(\boldsymbol{x})$ indicates the probability of mortality of an individual or litter, and $\boldsymbol{x}$, the level of inbreeding. Probabilities of mortality with the categorical traits were based on the least square means obtained from the output of SAS procedure GLIMMIX using the ilink option.

\section{RESULTS AND DISCUSSION}

The genetic variation of the reference population of Mhorr gazelle using PEDIG (Baumung et al, 2015) and ENDOG version 4.5 (Gutiérez and Goyache, 2005) are shown in Table 2. The reference population is composed of animals that are alive, with known parents and sex. A gazelle is considered alive when it is less than 10 years old (based on birth date) with no information on its death. This consideration is based on the approximate life span of Mhorr gazelle in captivity which is 12 years. The effective number of founders is 3.42 when half founder is to be counted and the effective number of ancestors is 3 . The analysis also showed that the effective number of founder genomes of the reference population is 1.44 which means that not all founders contributed equally but by approximately 2 founders. In this population, the effective number of founders and ancestors are lesser than the actual number of founders (8) and ancestors (8), which is an indication that there is an imbalance in the expected contribution of each founder in the population. The values on the effective number of founders and ancestors are almost equal indicating that the animals did not go through a severe bottleneck in captivity. However, the effective number of founder genomes is low (1.44), which demonstrates that there is gene loss in the reference population which could be due to genetic drift (Boichard et al., 1997) in addition to unequal founder contribution and bottleneck. The mean maximum generations indicate that, on average, a maximum of 6.97 generations could be traced back in the pedigree. 
Mean complete generation shows that there are approximately 4.11 complete generations which separate an individual from its farthest known ancestors. Moreover, each individual is separated by 4.94 generations on average (mean equivalent generations) from each of its known ancestors.

Table 2. Measures of genetic variation of Mhorr gazelle population in captivity.

\begin{tabular}{ll}
\hline Measures of genetic variation & Value \\
\hline No. of animals in the reference population (alive) & $97 / 315(30.79 \%)$ \\
Ne based on regression of equivalent generations & 7 \\
No. of founders & 8 (7.5 half founder) \\
Effective number of founders & 3.42 \\
No. of ancestors & 8 \\
Effective number of ancestors & 3 \\
No. of ancestors explaining 50\% of the genetic variation & 2 \\
Effective number of founder genomes & 1.44 (mean); 0.41 (SD) \\
Mean maximum generations & 6.97 \\
Mean complete generations & 4.11 \\
Mean equivalent generations & 4.94 \\
\hline
\end{tabular}

Table 3 shows the mean, standard deviation and maximum value of individual, sire and dam inbreeding coefficients of captive Mhorr gazelles. Approximately $70 \%$ of the individuals are inbred (219 out of 315$)$. The mean level of inbreeding in the population is $0.2971 \pm 0.1043$. This means that the individuals have $29.71 \%$ homozygous alleles that are identical by descent or $29.71 \%$ of the loci are homozygous for alleles which are single copies from a common ancestor of its parents (Thomas, 2015). The maximum inbreeding coefficient of an individual is $0.5247(52.47 \%)$. This shows that there is parent-offspring or full-sib mating in the population of interest in four to five generations (Vogt, Swartz \& Massey, 1993).

The influence of individual, sire and dam inbreeding on mortality at days 7, 30 and 180 (weaning age) is shown in Figure 1. Individual inbreeding has significantly increases mortality risk at day 180 or weaning age $(p<0.10)$. Analyses revealed that sire inbreeding is significant associated with increased mortality risk at day $30(p<$ 0.05). Dam inbreeding has no significant association on mortality risk at days 7,30 and 180.

Table 3. Total inbreeding coefficients $(f)$ of the individual, sire and dam of Mhorr gazelles in captivity.

\begin{tabular}{llcl}
\hline & Mean, $x$ & Standard deviation, $\sigma$ & Maximum \\
\hline Individual & 0.2971 & 0.1043 & 0.5247 \\
Sire & 0.2300 & 0.1141 & 0.4630 \\
Dam & 0.2339 & 0.1070 & 0.5221 \\
\hline
\end{tabular}




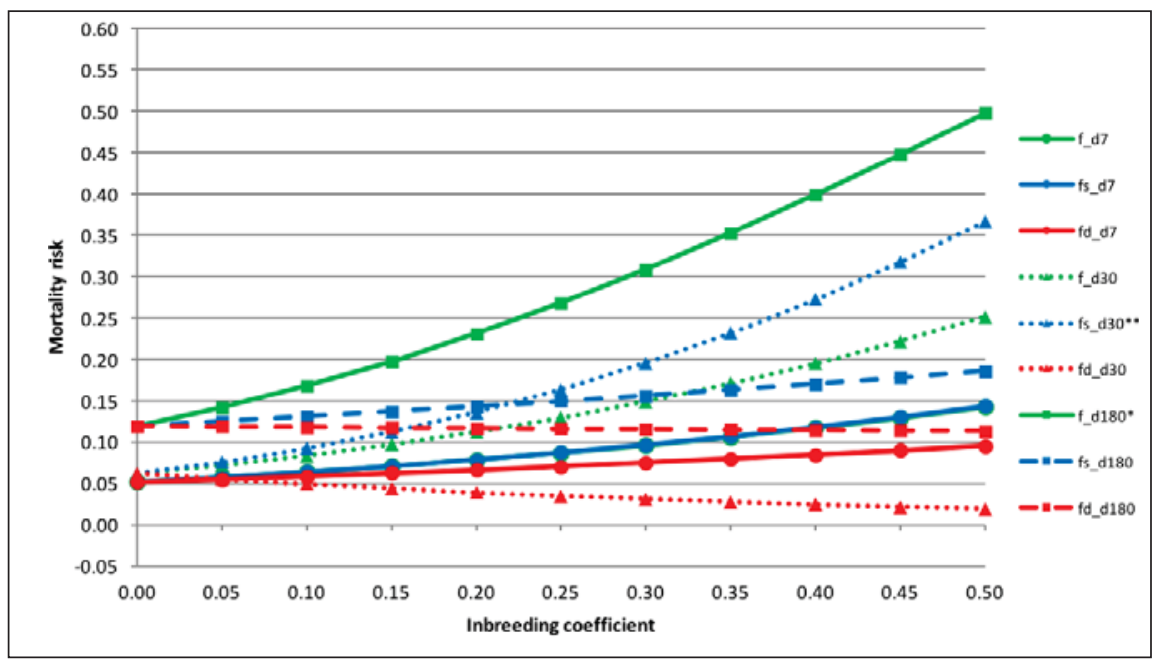

Figure 1. Mortality risk of an individual at days 7, 30 and $180 .{ }^{*} p<0.10,{ }^{* *} p<0.05$, ${ }^{* * *} p<0.01$, ${ }^{* * * *} p$ $<0.001) . \mathrm{f}=$ Individual inbreeding coefficient; $\mathrm{f}_{\mathrm{s}}=$ sire inbreeding coefficient; $\mathrm{f}_{\mathrm{d}}=$ dam inbreeding coefficient; $\mathrm{d} 7=$ day $7 ; \mathrm{d} 30=$ day $30 ;$ and $\mathrm{d} 180=$ day 180 .

Individual inbreeding is significantly associated with increasing mortality risk at day 180, which means that inbreeding level of an individual can influence survival (Figure 1). The increasing mortality risk associated with inbreeding level of an individual could be supported by the result found in the study of Cassell et al. (2003) in which inbreeding has negative effect on fitness traits such as survival in Holstein and Jersey cattle. Cassell et al. found out that inbreeding of the calf is the one affecting its survival at later stages of life and not the inbreeding of the sire or dam. Furthermore, reports on zoo and wild animals also showed that an inbred has declined survival compared to non-inbred (Bales et al., 2001; Brown \& Brown, 1998; Cassinello, 2005; Ralls, et al., 1979; Ballou \& Ralls, 1982; Packer \& Pusey, 1993; Ralls et al.,1979; Ralls and Ballou, 1982a and Ralls and Ballou 1982b). The inbreeding effects on survival could be a manifestation of inbreeding depression due to an increase in homozygosity of deleterious alleles (Crnokrak \& Roff, 1999; Read \& Harvey, 1986; and Wright et al., 2008).

Inbred sires were found to be significantly associated with increasing risk in mortality at day 30. On the other hand, the result of the study of Cassinello (2005) where maternal inbreeding had a negative relationship with longevity and inbreeding in male Mhorr gazelles is not totally the same with the results obtained in this study. This could be due to the fact that in this study, the effect of inbreeding on survival of male and female offspring was not compared, and the specific age of mortality was specified in the analysis. Furthermore, Byers and Waits (2006), in their study with pronghorns, which are also artiodactyls, mentioned that in the wild, females use other information aside from male ornaments in selecting superior mates. This information includes remarkable robustness indicating that these males have low number of small-effect deleterious mutations which makes them genetically superior. However, in this captive population, females do not have enough chance of choosing a genetically superior male to produce offspring with lower risk of mortality because of the smaller population size and zoo 
breeding scheme. In addition, sires in this captive population most likely are inbred, thus having an influence on the survival of their offspring.

\section{CONCLUSIONS}

There is substantial gene loss in the Mhorr gazelle captive population with the number of founder genomes (1.44) is less than the effective number of founders (3.42) and ancestors (3) attributable to unequal founder contribution, genetic bottleneck and random genetic drift. The population has not gone through a severe bottleneck as indicated by the almost equal values of the effective number of founders and ancestors. Among those three factors influencing genetic variation, bottleneck can be minimized by providing optimum animal care and random genetic drift can be lessened by increasing the frequency of genetic resource exchange from different zoos.

An increasing inbreeding level of an individual significantly increases mortality risk at weaning age (day 180) while an inbred sire has a significant effect on increasing the mortality risk of an individual at day 30. However, mortality can also be due to non-inbreeding causes, thus, a combination of best possible zoo management and efficient breeding programs is highly important in improving the survival rates of these animals kept in captivity. Generally, breeding programs should still be designed to reduce the rate of inbreeding and maximize genetic variation since inbreeding might be an important factor for mortality also in other populations and species.

\section{ACKNOWLEDGMENT}

The authors thank Dr. Elizabeth Boakes of the NERC Centre for Population Biology, Imperial College, Berkshire, UK; Ros Wilkins, Species Management Officer of ARAZPA; Prof. Dr. Hossein Jorjani of the Department of Animal Breeding and Genetics, Swedish University of Agricultural Sciences and Erasmus Mundus (European Masters in Animal Breeding and Genetics Program) for the scholarship grant.

\section{REFERENCES}

AGRESTI, A. 2002. Catergorical Data Analysis, $2^{\text {nd }}$ Ed. John Wiley and Sons, Inc., New Jersey

BAIS, L. 2002. "Panthera pardus" (On-line), Animal Divesrity Web. Accessed May 20, 2009 at http://animaldiversity.ummz.umich.edu/site/ accounts/information/Panthera_pardus.html

BALLOU, J. and K. RALLS. 1982. Inbreeding and juvenile mortality in small populations of ungulates. A detailed analysis. Biological Conservation 24 (4), 239-272.

BAUMUNG, R., FARKAS, J., BOICHARD'D., MÉSZÁROS, G., SÖLKNER, J. and CURIK, I. 2015. GRAIN: a computer program to calculate ancestral and partial inbreeding coefficients using a gene dropping approach. Journal of Animal Breeding and Genetics 132 (2), 100-108. 
BOICHARD, D, MAINGEL, L. and E. VERRIER. 1997. The value of using probabilities of gene origin to measure genetic variability in a population. Genetic Selection Evolution 29: 5-23.

BROWN, J.L. and E.R. BROWN. 1998. Are inbred offsrping less fit? Survival in a natural population of Mexican jays. Behavioral Ecology $\mathbf{9}$ (1), 60-65

BYERS, J. A. and L. WAITS. 2006. Good genes sexual selection in nature. Proceedings of the National Academy of Sciences of the United States of America 103 (44), 16343-16345.

CASSELL, B. G., ADAMEC, V. and R.E. PEARSON, R. E. 2003. Maternal and fetal inbreeding depression for 70-day nonreturn and calving rate in Hosteins and Jerseys. Journal of Dairy Science 86 (9), 2977-2983.

CASSINELLO, J. 2005.Inbreeding depression on reproductive performance and survival in captive gazelles of great conservation value. Biological Conservation 122, 453-464.

CRNOKRAK, P., and D.A. ROFF. 1999. Inbreeding depression in the wild. Heredity 83(3), 260-270

FALCONER, D. S. and T.F.C. MACKAY. 1996. Introduction to Quantitative Genetics, $4^{\text {th }}$ Ed. Longman Group Ltd., England.

FRANKHAM, R., GILLIGAN, D. M., MORRIS, D. and D.A. BRISCOE. 2001. Inbreeding and extinction: Effects of purging. Conservation Genetics 2, 279-285.

GUTIÉRREZ, J. P. and F. GOYACHE. 2005. A note on ENDOG: a computer program for analysing pedigree information. Journal of Animal Breeding and Genetics 122 (3), 172-176.

HEDRICK, P. W. 1994. Purging inbreeding depression and the probability of extinction: full-sib mating. Heredity 73, 363-372.

HEDRICK, P.W. and S.T. KALINOSWKI. 2000. Inbreeding depression in conservation biology. Annual Review of Ecology and Systematics 31, 139-162.

LACY, R.C. 1993. Impacts of inbreeding in natural and captive populations of invertebrates: implications for conservation. Perspectives in Biology and Medicine $36(3), 480-496$.

LACY, R. C. (1995). Clarification of genetic terms and their use in the management of vaptive populations. Zoo Biology14 (6), 565-578.

LACY, R. C., ALAKS, G. and A. WALSH. 1996. Hierarchical analysis of inbreeding depression in Peromyscus polionotus. Evolution 50 (6), 2187-2200

NEWBY, J., WACHER, T., LAMARQUE, CUZIN, F. and K. DE SMET. 2008. Nanger dama. In: IUCN 2008. 2008 IUCN Red List of Threatened Species.

PACKER, C. and A.E. PUSEY. 1993. Dispersal, kinship and inbreeding in African lions: In N.W. Thornhill (Ed.), The Natural History of Inbreeding and Outbreeding: Theoretical and Empirical Perspectives (pp. 67-86). University of Chicago Press, Chicago, Illinois

RALLS, K. BRUGGER, K. and J. BALLOU. 1979. Inbreeding and juvenile mortality in small populations of ungulates. Science 206 (4422), 1101-1103

RALLS, K. and J. BALLOU. 1982a. Effect of inbreeding on juvenile mortality in some small mammal species. Laboratory Animals (16)2, 159-166.

RALLS, K. and J. BALLOU. 1982b. Effects of inbreeding on infant mortality in captive primates. International Journal of Primatology (3)4, 491-505 
RAMIREZ, O., ALTET, L., ENSENAT, C., VILÁ, C., SANCHEZ, A. and A. RUIZ. 2006. Genetic assessment of the Iberian wolf Canis lupus signatus captive breeding program. Conservation Genetics 7, 861-878.

READ, A. F. and P.H. HARVEY. 1986. Genetic management in zoos. Nature 322 (6078), 408-410.

THOMAS, D.L. 2015. Mating systems: Inbreeding and inbreeding depression. In H. Khatib (Ed.), Molecular and Quantitative Animal Genetics. John Wiley \& Sons, Inc., New Jersey

VOGT, D., SWARTZ, H.A., and J. MASSEY, J. 1993. Inbreeding: Its meaning, uses and effects on farm animals. Retrieved from University of Missouri, MU Extension

WRIGHT, L. I., TREGENZA, T and D. J. HOSKEN, D. 2008. Inbreeding, inbreeding depression and extinction. Conservation Genetics 9, 833-843. 